\title{
DAMPAK VARIASI MODEL PROPAGASI TERHADAP PROTOKOL ROUTING REAKTIF, PROAKTIF, DAN HYBRID DI JARINGAN VANET (STUDI KASUS KOTA BIMA)
}

\author{
(Impact of Propagation Model Variations on Reactive, Proactive and Hybrid Routing \\ Protocols in the VANET Network (Case Study of the City of Bima))
}

\author{
Nazibullah", Andy Hidayat Jatmika, Fitri Bimantoro \\ Program Studi Teknik Informatika, Fakultas Teknik, Universitas Mataram \\ JI. Majapahit 62, Mataram, Lombok NTB, INDONESIA \\ Email: nazib.yahya@gmail.com, [andy, bimo]@unram.ac.id
}

\begin{abstract}
VANET is a subset of Mobile Adhoc Network (MANET) that utilizes wireless technology, which in the VANET network the node is presented as a vehicle and the route for a vehicle is presented as a highway that will be passed by that vehicle. In general, VANET has 3 classification routing protocols, namely reactive, proactive, and hybrid. Performance of routing protocol is greatly influenced by the propagation model. Propagation on the network is the behavior of radio waves, which in this case is used as a transmission medium from the transmitter to the destination (receiver). This research will analyze the variation of propagation models namely FreeSpace, TwoRayGround, Shadowing, and Nakagami on the performance of AOMDV (reactive), OLSR (proactive), and ZRP (hybrid). The performance of the routing protocol will be tested using test parameters including Packet Delivery Ratio (PDR), Packet Loss, End to End Delay, and Throughput.
\end{abstract}

Keywords: VANET, AOMDV, OLSR, ZRP, FreeSpace, TwoRayGround, Shadowing, Nakagami

*Penulis Korespondensi

\section{Pendahuluan}

Teknologi informasi saat ini mengalami perkembangan cukup cepat, seiring dengan hal tersebut telah banyak penelitian yang dilakukan untuk mencari alternatif jalan keluar untuk masalah seharihari. Salah satu masalah yang banyak ditemukan terutama di kota-kota khususnya di jalan raya adalah kemacetan, kecelakaan lalu lintas, pencarian rute alternatif, dan lain-lain, banyak penelitian yang dilakukan mencari solusi masalah ini, salah satunya adalah dengan memanfaatkan teknologi Vehicular Adhoc Network (VANET), dengan VANET kendaraankendaraan dapat bertukar informasi mengenai kondisi lalu lintas jalan raya.

VANET merupakan subset Mobile Adhoc Network (MANET) yang memanfaatkan teknologi wireless, yang dimana pada jaringan VANET node direpresentasikan sebagai kendaraan sedangkan rute untuk kendaraan direpresentasikan sebagai jalan raya yang akan dilalui oleh kendaraan tersebut. VANET mempunyai karakteristik jaringan dengan mobilitas tinggi dan pergerakan node yang tidak dapat ditentukan, oleh karenanya topologi akan mengalami perubahan secara cepat. Di dalam VANET terdapat 3 klasifikasi protokol jaringan yaitu protokol routing reaktif, proaktif, dan hybrid. Kinerja VANET juga sangat dipengaruhi oleh model propagasi [1]. Propagasi pada jaringan merupakan perilaku atau proses perambatan gelombang radio, yang dalam hal ini berfungsi sebagai media transmisi dari pengirim (transmitter) ke tujuan (receiver).

Tujuan penelitian ini adalah melihat gambaran bagaimana pengaruh variasi model propagasi antara lain adalah Free Space, TwoRayGround, Shadowing, dan Nakagami terhadap protokol-protokol routing $A d$ Hoc on Demand Multipath Distance Vector (AOMDV) yang mewakili jenis protokol routing reaktif, Optimized Link State Routing (OLSR) yang mewakili jenis protokol routing proaktif, dan Zone Routing Protocol (ZRP) yang mewakili jenis protokol routing hybrid jika diterapkan pada peta jalan Kota Bima. Dari masing-masing ketiga protokol routing tersebut yakni AOMDV, OLSR, dan ZRP akan diimplemetasikan jenisjenis variasi model propgasi dan dilihat bagaimana pengaruh variasi model propagasi tersebut terhadap masing-masing protokol routing apabila diterapkan pada peta jalan kota Bima.

AOMDV merupakan protokol routing reaktif yang memiliki unjuk kerja yang lebih bagus bila 
dibandingkan dengan protokol routing reaktif jenis lain seperti AODV apabila menggunakan MAC type IEEE 802.11p yang dimana MAC type IEEE 802.11p ini dinilai cocok apabila digunakan pada jaringan VANET [2]. OLSR merupakan protokol routing proaktif yang memiliki performa yang lebih baik bila dibandingkan dengan protokol routing jenis proaktif lain dalam jaringan VANET seperti DSDV dalam parameter uji Packet Delivery Ratio, End to End Delay, dan Routing Overhead [3]. ZRP merupakan protokol routing jenis hybrid memiliki performa yang baik dibandingkan dengan protokol routing GPSR dari segi Packet Delivery Rasio (PDR) dan Packet Loss pada jaringan VANET [4].

Berdasarkan data Badan Pusat Statistik (BPS) Kota Bima tahun 2017 jumlah kendaraan baik kendaraan bermotor maupun tidak bermotor yang terdapat di Kota Bima adalah sebanyak 51.269 unit, dengan jumlah kendaraan sebanyak itu akan berpotensi menimbulkan kemacetan serta kecelakaan lalu lintas. Sehingga diperlukan suatu solusi jalan keluar untuk mengatasi permasalahan-permasalah tersebut, oleh sebab itu lalu lintas Kota Bima dinilai cocok apabila dijadikan sebagai objek pada penelitian ini. Parameter uji kinerja yang digunakan pada penelitian ini adalah Packet Loss yaitu jumlah paket yang hilang selama proses simulasi, End to End Delay yaitu waktu yang diperlukan selama pengiriman paket data dari sumber ke tujuan, dan Troughput yaitu jumlah total kedatangan paket yang sukses yang diamati pada tujuan selama interval waktu tertentu dibagi oleh durasi interval waktu tersebut. Pada penelitian ini ini akan dilakukan simulasi jaringan VANET menggunakan tool software Simulator Network 2 (NS2) dan Simulation for Urban Mobility (SUMO). Rute yang digunakan adalah peta jalan Kota Bima yang diambil pada situs web OpenStreetMap. Hasil yang diharapkan dari penelitian ini adalah bagaimana pengaruh model propagasi terhadap protokol routing reaktif, proaktif, hybrid pada jaringan VANET.

\section{TinjauAn PUSTAKA}

Pada penelitian [5] oleh Khalid Abdel Hafeez, Lian Zhao, Zaiyi Liao, dan Bobby Ngok-Wah Ma, dilakukan analisis terhadap kinerja model propagasi TwoRayGround, Nakagami, dan Shadowing dengan parameter simulasi yang dilakukan adalah jumlah node sebanyak 12 node/ $\mathrm{km} /$ lane, kecepatan gerak node $70-120 \mathrm{~km} / \mathrm{h}$ pada peta dengan kondisi lingkungan perkotaan (urban). hasilnya adalah model propagasi TwoRayGround mengalami waktu delay yang terbesar bila dibandingkan dengan model propagasi lainnya (Shadowing dan Nakagami).

Pada penelitian [6] oleh Dhiya'an Sabila Ramadhani dan Radityo Anggoro, dilakukan sebuah studi perbandingan model propagasi TwoRayGround dan Nakagami menggunakan protokol routing OLSR dengan parameter simulasi menggunakan 50 node, kecepatan maksimal node $5 \mathrm{~m} / \mathrm{s}, 10 \mathrm{~m} / \mathrm{s}, 15 \mathrm{~m} / \mathrm{s}$ serta luas area simulasi adalah $510 \times 510$ meter. Pada penelitian ini dilakukan perbandingan antara model propagasi menggunakan protokol routing OLSR dengan parameter uji yang digunkan adalah Packet Delivery Ratio (PDR), End to End Delay, dan Routing Overhead. Hasil yang didapat pada penelitian ini adalah pada parameter uji Packet Delivery Ratio (PDR) dan End to End Delay performa model propagasi Nakagami lebih baik dibandingkan dengan TwoRayGround. Untuk parameter uji Routing Overhead model progasi TwoRayGround memiliki nilai yang lebih besar dibandingkan dengan Nakagami, hal ini terjadi karena pengiriman paket routing jenis send dan forward yang dilakukan oleh TwoRayGround lebih banyak dari Nakagami.

Pada penelitian [7] oleh Ramesh C. Poonia dan Vikram Singh, dilakukan perbandingan terhadap kinerja beberapa variasi model propagasi yaitu diantaranya model propagasi Free Space, TwoRayGround, Shadowing, dan Nakagami. Adapun parameter simulasi yang ditentukan pada penelitian tersebut adalah menggukan area simulasi $1000 \times 1000$ $\mathrm{m}$, jumlah variasi node yang dipakai adalah $10,50,75$, $100,125,150,175$, dan 200, pada peta dengan kondisi lingkungan urban (perkotaan), dan menggunakan protokol routing AODV, waktu simulasi yang digunakan 100 detik, dan kecepatan pergerakan node adalah antara 8.33-13.89 meter/detik. Parameter pengujian yang digunakan untuk menguji kemampuan masing-masing model propagsi adalah Throughput, Packet Loss, Transmitted Packet, dan Received Packet. Hasil yang diperoleh dari simulasi penelitian ini menunjukan bahwa model propagasi Nakagami memiliki performa yang paling baik dibandingkan ketiga model propagasi lainnya, baik itu berdasarkan nilai Throughput, Packet Loss, Transmitted Packet, maupun Recived Packet.

Pada penelitian [8] oleh Bhargav Makodia dan Dhruvi Marsonia, dilakukan perbandingan beberapa variasi model propagasi yaitu Free Space, TwoRayGround, dan Shadowing pada protokol routing AODV, dengan parameter simulasi yang digunakan adalah kecepatan pergerakan node berada di kisaran antara $1 \mathrm{~m} / \mathrm{s}$ sampai $40 \mathrm{~m} / \mathrm{s}$, jumlah node berkisar 
antara 5 hingga 40 node, dengan parameter ukur yaitu Packet Delivery Ratio (PDR), End to End Delay (E2D), dan Througput. Hasil yang didapat pada penelitian ini bahwa pada parameter ukur PDR model propagasi Shadowing memiliki hasil yang baik, namun seiring dengan bertambahnya jumlah node maka model propagasi Free Space memilki performa yang lebih baik. Untuk Througput rata-rata Shadowing model memiliki nilai yang terbaik dari kedua model propagasi lainnya. Sedangkan untuk parameter ukur E2D model propagasi Free Space memilki nilai yang baik diikuti dengan model Shadowing.

\section{Metode Penelitian}

\subsection{Identifikasi Kebutuhan Sistem}

Berikut merupakan identifikasi kebutuhan perangkat keras dan perangkat lunak yang akan digunakan dalam simulasi penelitian.

a. Sebuah laptop sebagai alat untuk melakukan aktifitas penelitian seperti melakukan simulasi dan pembuatan laporan.

b. Sistem operasi Linux Ubuntu 16.04 LTS 32 bit.

c. Network Simulator 2 (NS2) versi 2.35 yang digunakan untuk simulasi proses komunikasi antar node atau kendaraan

d. Simulation of Urban Mobility (SUMO) versi 1.0 yang digunakan untuk membangun simulasi pergerakan node.

e. Microsoft Excel untuk membuat grafik hasil simulasi

f. Java OpenStreetMap (JSOM) untuk menyunting peta sesuai kebutuhan

\subsection{Diagram Alir Penelitian}

Pada 3.1 berikut ini digambarkan bagaimana proses penelititan berlangsung dari awal dimulainya proses penelitian hingga akhir.

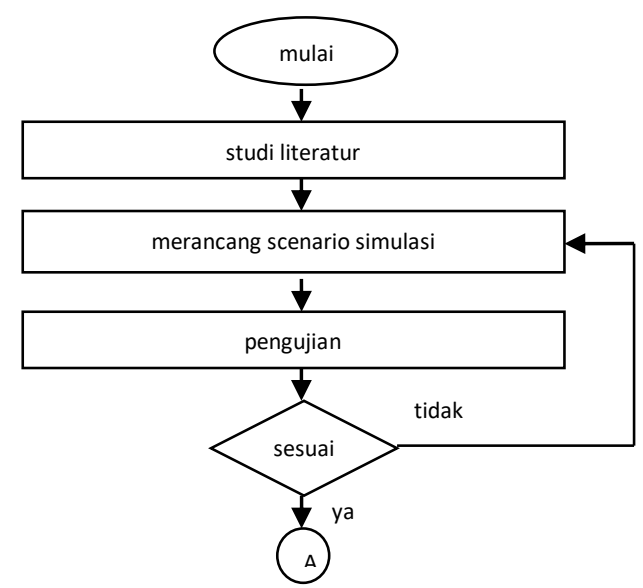

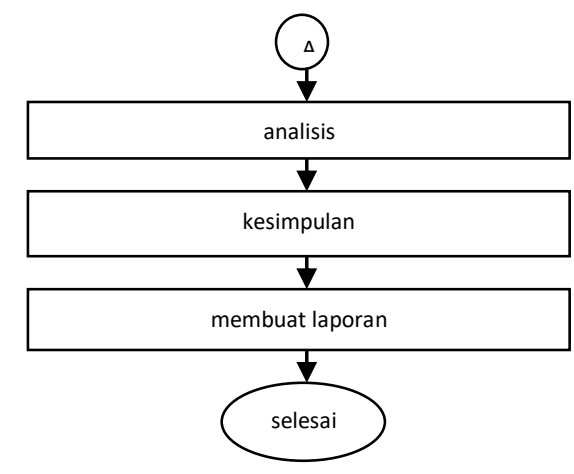

Gambar 1. Diagram Alir Penelitian

\subsection{Parameter Simulasi}

Pada tabel berikut merupakan parameter simulasi yang dilakukan pada proses penelitian. Parameter berikut ini mengacu pada penelitian [2] yang kemudian disesuaikan dengan kebutuhan pada penelitian. Selengkapnya disajikan pada tabel 1 sebagai berikut

TABEL 1. PARAMETER SIMULASI

\begin{tabular}{|l|l|}
\hline \multicolumn{1}{|c|}{ Parameter } & \multicolumn{1}{c|}{ Nilai } \\
\hline Protokol Routing & AOMDV, OLSR, dan ZRP \\
\hline Model Propagasi & $\begin{array}{l}\text { Free Space, TwoRayGround, } \\
\text { Shadowing, dan Nakagami } \\
\text { Area Simulasi }\end{array}$ \\
\hline Protokol Pengiriman & UDP \\
\hline Model Trafik & CBR \\
\hline Jumlah Node & 30,50, dan 70 \\
\hline Kecepatan Node & $90 \mathrm{~km} / \mathrm{h}$ \\
\hline Pergerakan Node & Random Waypoint \\
\hline Kanal & Wireless \\
\hline Antena & OmniAntenna \\
\hline MAC Layer & IEEE 802.11p \\
\hline
\end{tabular}

\section{HASIL DAN PEMBaHASAN}

Berikut ini merupakan hasil dari simulasi yang dilakukan pada protokol routing AOMDV, OLSR, dan ZRP yang dipangaruhi oleh berbagai macam model propagasi yang kemudian diukur menggunakan parameter uji antara lain Packet Loss, Throughput, dan End to end delay. 


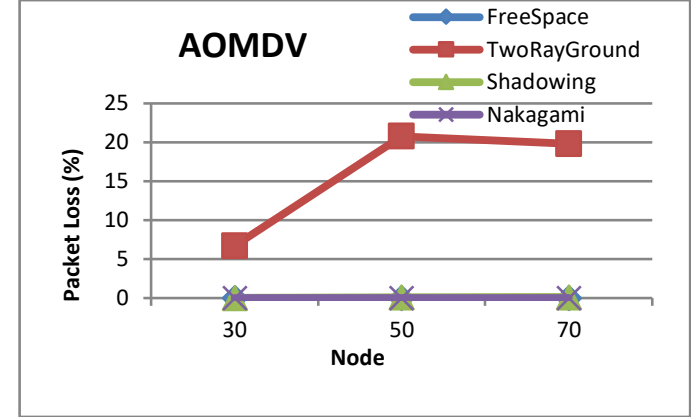

(a)

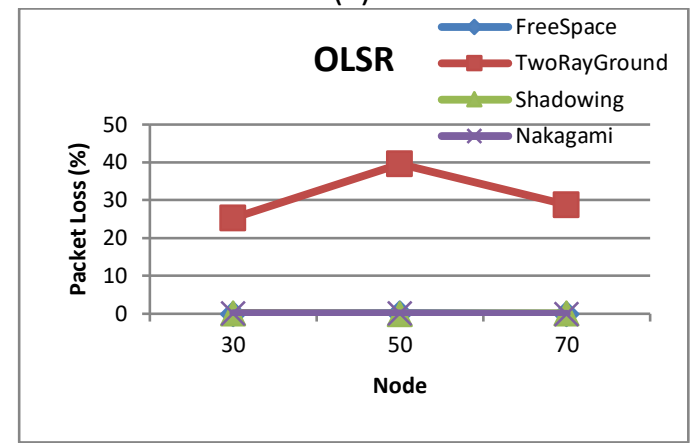

(b)

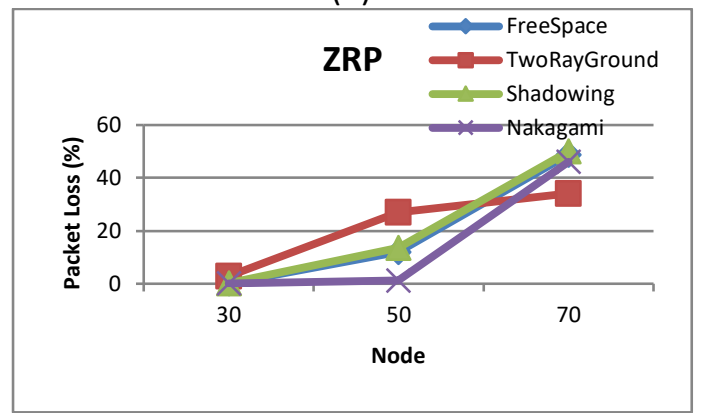

(c)

Gambar 2. Perbandingan nilai rata-rata packet loss. (a) grafik perbandingan nilai packet loss protokol routing AOMDV; (b) grafik perbandingan nilai packet loss protokol routing OLSR; (c) grafik perbandingan nilai packet loss protokol routing ZRP

Pada gambar 2 grafik (a) menunjukan bahwa apabila menggunakan protokol routing AOMDV, propagasi TwoRayGround menghasilkan nilai packet loss yang lebih besar untuk semua variasi jumlah node, nilai packet loss terbesar terjadi pada variasi jumlah 50 node yaitu $20.761 \%$. Sedang untuk propgasi FreeSpace, Shadowing, dan Nakagami nilai packet loss hampir sama dan tidak mengalami perubahan signifikan untuk semua variasi jumlah node. Grafik (b) menunjukan bahwa apabila menggunakan protokol routing OLSR, propagasi TwoRayGround menghasilkan nilai packet loss yang lebih besar untuk semua variasi jumlah node, nilai packet loss terbesar terjadi pada variasi jumlah 50 node yaitu $39.564 \%$.
Sedang untuk propgasi FreeSpace, Shadowing, dan Nakagami nilai packet loss hampir sama dan tidak mengalami perubahan signifikan untuk semua variasi jumlah node. Grafik (c) menunjukan bahwa apabila menggunakan protokol routing ZRP, unutk semua jenis propagasi nilai packet loss akan bertambah seiring dengan bertambahnya jumlah node, akan tetapi hasil terbesar tunjukan oleh propagasi Shadowing pada variasi 70 node dengan nilai $50.008 \%$, sedangkan hasil terkecil ditunjukan oleh propagasi FreeSpace pada variasi jumlah 30 node dengan nilai $0.077 \%$.
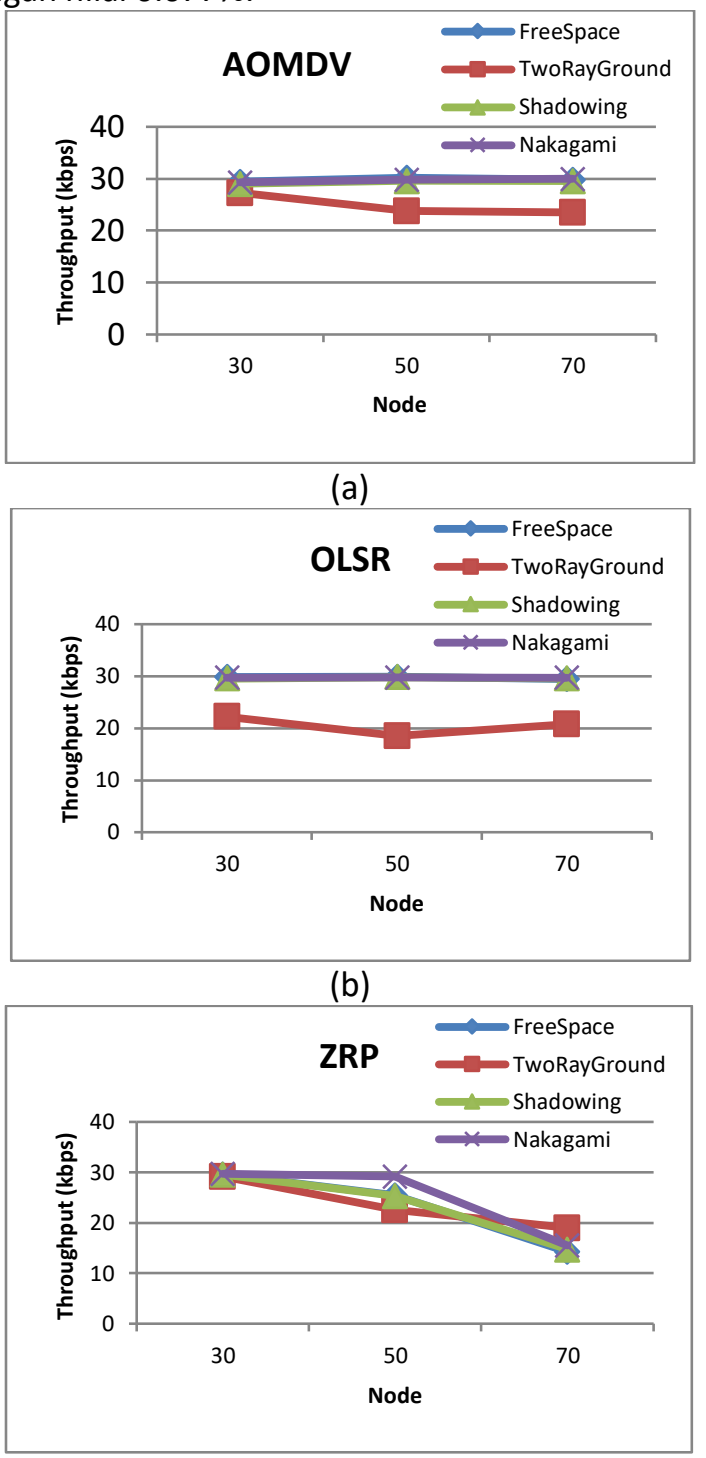

(c)

Gambar 3. Perbandingan nilai rata-rata throghput. (a) grafik perbandingan nilai throughput protokol routing AOMDV; (b) grafik perbandingan nilai throughput protokol routing OLSR; (c) grafik perbandingan nilai throughput protokol routing ZRP; 
Pada Gambar 3 grafik (a) menunjukan bahwa apabila menggunakan protokol routing AOMDV, propagasi TwoRayGround memiliki nilai throughput yang lebih rendah untuk semua variasi jumlah node, nilai paling rendah ditunjukan pada variasi jumlah 70 node dengan nilai 23.509 kbps. Sedangkan untuk propagasi FreeSpace, Shadowing, dan Nakagami memili nilai throughput yang hampir sama dan tidak mengalami perubahan signifikan untuk semua variasi jumlah node, akan tetapi hasil tertinggi ditunjukan oleh propagasi Nakagami pada variasi jumlah 70 node dengan nilai 29.999 kbps. Grafik (b) menunjukan bahwa apabila menggunakan protokol routing OLSR, propgasi TwoRayGround memiliki nilai throughput yang lebih rendah untuk semua variasi jumlah node, nilai paling rendah ditunjukan pada variasi jumlah 50 node dengan nilai 18.519 kbps. Sedangkan untuk propagasi FreeSpace, Shadowing, dan Nakagami memili nilai throughput yang hampir sama dan tidak mengalami perubahan signifikan untuk semua variasi jumlah node, akan tetapi hasil tertinggi ditunjukan oleh propagasi Shadowing pada variasi jumlah 50 node dengan nilai 29.779 kbps. Grafik (c) menunjukan bahwa apabila menggunakan protokol routing ZRP, untuk semua jenis propagasi nilai throughput akan berkurang seiring dengan bertambahnya jumlah node, akan tetapi hasil terbesar ditunjukan oleh propagasi Nakagami dengan nilai 29.722 kbps, sedangkan nilai terkecil ditunjukan oleh propagasi FreeSpace dengan nilai 14.262 kbps.
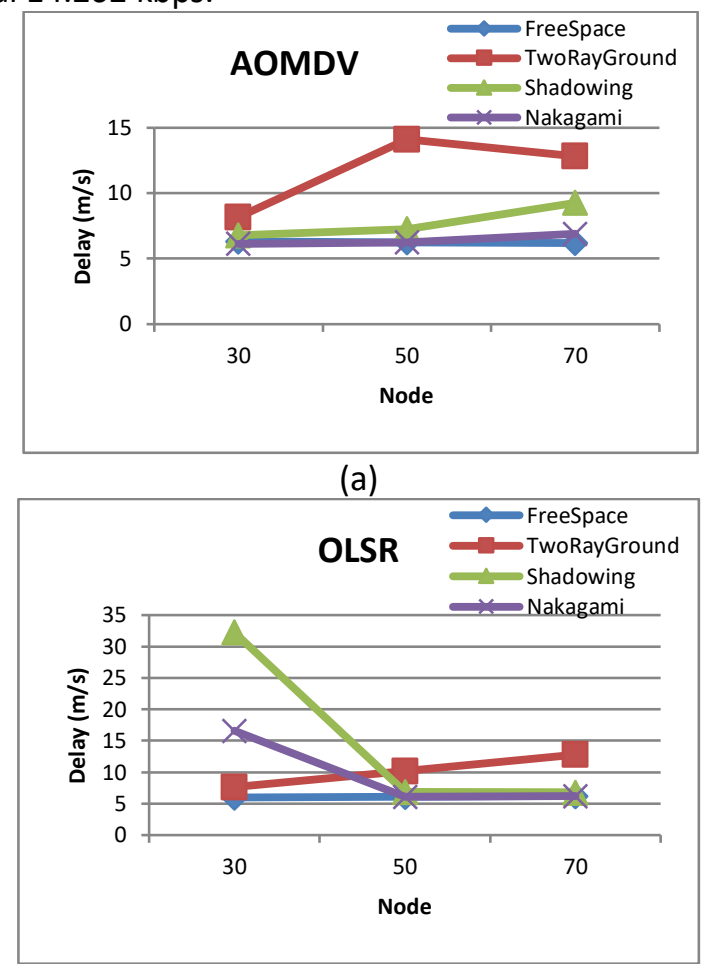

(b)

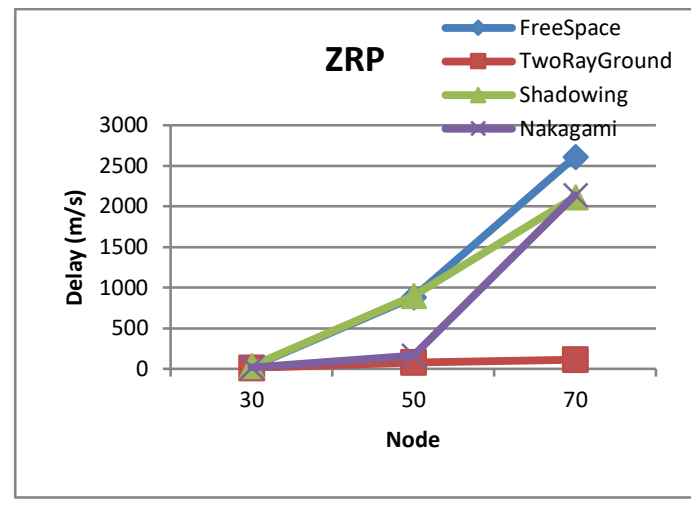

(c)

Gambar 4. Perbandingan nilai rata-rata end to end delay. (a) grafik perbandingan nilai end to end delay protokol routing AOMDV; (b) grafik perbandingan nilai end to end delay protokol routing OLSR; (c) grafik perbandingan nilai end to end delay protokol routing ZRP;

Pada Gambar 4 grafik (a) menunjukan bahwa apabila menggunakan protokol routing AOMDV, propagasi TwoRayGround memiliki nilai end to end delay yang paling besar pada semua variasi jumlah node, nilai terbesar ditunjukan pada variasi jumlah 50 node yaitu $14.119 \mathrm{~m} / \mathrm{s}$. Sedangkan nilai terkecil ditunjukan oleh propagasi Nakagami pada variasi jumlah 30 node dengan nilai 6.1313 m/s. Grafik (b) menujukan bahwa apabila menggunakan protokol routing OLSR, propagasi Shadowing memiliki nilai end to end delay yang paling besar, yaitu pada variasi jumlah 30 node dengan nilai 32.239 m/s, sedangkan nilai terkecil ditunjukan propagasi FreeSpace pada variasi jumlah 30 node yaitu dengan nilai 5.9856 m/s. Grafik (c) menunjukan bahwa apabila menggunakan protokol routing ZRP, untuk semua jenis propagasi nilai end to end delay mengalami peningkatan seiring dengan bertambahnya jumlah node, akan tetapi nilai terbesar ditunjukan oleh propagasi FreeSpace pada variasi jumlah 70 node dengan nilai $2609.4 \mathrm{~m} / \mathrm{s}$, sedangkan nilai terkecil ditunjukan oleh propagasi TwoRayGround dengan nilai $11.708 \mathrm{~m} / \mathrm{s}$ pada variasi jumlah 30 node.

\section{Kesimpulan dan SARAN}

\section{1. Kesimpulan}

Setelah dilakukan proses analisis terhadap hasil simulasi jaringan VANET terhadap protokol routing AOMDV, OLSR, dan ZRP dengan menggunakan peta jalan kota Bima, maka didapat kesimpulan sebagai berikut: 
a. Berdasarkan packet loss protokol routing AOMDV dan OLSR mendapatkan nilai rata-rata sebesar $0 \%$ untuk semua variasi jumlah node pada propagasi Nakagami untuk AOMDV dan propagasi FreeSpace untuk OLSR, sedangkan ZRP mendapatkan nilai minimum sebesar $0.077 \%$ pada propagasi FreeSpace node 30 .

b. Nilai rata-rata throughput protokol routing AOMDV terbaik yaitu menggunakan jenis propagasi Free Space yaitu 30.191 kbps pada node 50. Pada protokol routing OLSR hasil rata-rata terbaik kembali pada jenis propagasi Free Space dengan 29.9 kbps pada node 50 . Sedangkan pada protokol routing ZRP propagasi Nakagami unggul dengan nilai 29.722 kbps pada node 30 .

c. Nilai rata-rata delay terbaik untuk masingmasing protokol routing AOMDV, OLSR, dan ZRP secara berurutan adalah $6.1313 \mathrm{~m} / \mathrm{s}$ pada jumlah node 30 propagasi Nakagami, 5.9856 $\mathrm{m} / \mathrm{s}$ pada jumlah node 30 propagasi FreeSpace, $11.708 \mathrm{~m} / \mathrm{s}$ pada jumlah node 30 propagasi TwoRayGround.

d. Berdasarkan keseluruhan hasil percobaan simulasi yang digunakan pada peta jalan kota Bima protokol routing paling cocok diterpakan adalah AOMDV sedangkan untuk jenis propagasinya adalah Nakagami.

\section{2. Saran}

Berdasarkan kesimpulan yang telah dipaparkan tersebut, maka dapat diusulkan beberapa saran berikut demi pengembangan kedepannya, seperti:

a. Melakukan penelitian yang serupa dengan mengimplementasikan algoritma tambahan serta menggunakan simulator jenis lain seperti OMNet++ dan NS3.

b. Melakukan penelitian menggunakan protokol routing selain AOMDV, OLSR, dan ZRP.

\section{DAFTAR PUSTAKA}

[1] V. D. Khairnar and K. Kotecha, "Propagation Models For V2v Communication In Vehicular Ad-Hoc Networks," J. Theor. Appl. Inf. Technol., vol. 61, no. 3, pp. 686-695, 2014.

[2] S. Dubey, A. Nema, and A. Verma, "AODV and AOMDV Routing Protocol with 801 . 11p in VANET," Int. J. Adv. Res. Comput. Sci. Softw. Eng., vol. 6, no.
6, pp. 136-140, 2016.

[3] M. D. Agustya, R. Anggoro, and H. Studiawan, "Analisis Performa Proactive Routing Protocol DSDV dan OLSR pada Vehicular Ad hoc Network (VANET) Menggunakan NS-3," 2015.

[4] D. S. Ramadhani et al., "Analisis Performa Proactive Routing Protocol DSDV dan OLSR pada Vehicular Ad hoc Network ( VANET ) Menggunakan NS-3," J. Tek. ITS, vol. 61, no. 2, pp. 686-695, 2016.

[5] K. A. Hafeez, L. Zhao, Z. Liao, and B. N. W. Ma, "The optimal radio propagation model in VANET," 4th Int. Conf. Syst. Networks Commun. ICSNC 2009, pp. 6-11, 2009.

[6] D. S. Ramadhani and R. Anggoro, "Studi Perbandingan Kinerja Model Transmisi TwoRayGround dan Nakagami pada OLSR di Lingkungan MANET Menggunakan NS-2," J. Tek. ITS, vol. 5, no. 2, 2016.

[7] R. C. Poonia and V. Singh, "Performance Evaluation of Radio Propagation Model For Vehicular Ad Hoc Metworks Using VanetMobisim And NS-2," Int. J. Distrib. Parallel Syst., vol. 3, no. 4, pp. 145-155, 2012.

[8] B. Makodia and D. Marsonia, "Effect of Radio-Wave Propagation Model On Network Performance with AODV Routing Protocol For IL-VANET," Int. Arch. Appl. Sci. Technol., vol. 5, pp. 13-18, 2014.

[9] Y. A. Pranata, I. Fibriani, and S. B. Utomo, "Analisis Optimasi Kinerja Quality of Service Pada Layanan Komunikasi Data Menggunakan NS - 2 di PT . PLN ( Persero ) Jember," vol. 20, no. 2, pp. 149-156, 2016.

[10] R. Kumar and M. Dave, "A Comparative Study of Various Routing Protocols in VANET," IJCSI Int. J. Comput. Sci. Issues, vol. 8, no. 4, pp. 643-648, 2011.

[11] R. Hadiwiriyanto, P. H. Trisnawan, and K. Amron, "Implementasi Protokol Geographic Source Routing (GSR ) Pada Vehicular Ad-Hoc Network ( VANET ) untuk Komunikasi Kendaraan Dengan Road Side Unit ( RSU )," J. Penegembangan Teknol. Inf. dan IImu Komput., vol. 2, no. 12, pp. 7007-7016, 2018.

[12] K. Kamarullah, Endroyono, and Wirawan, "Optimasi Cross Layer Untuk Protokol Dynamic Source Routing Pada Komunikasi Antar Kendaraan Berbasis Vehicular Ad-Hoc Networks ( VANETs )," J. Tek. ITS, vol. 6, no. 2, pp. 443-448, 2017.

[13] R. Wulandari, "Analisis Qos ( Quality Of Service ) Pada Jaringan Internet ( Studi Kasus : UPT Loka Uji Teknik Penambangan Jampang Kulon - Lipi )," J. Tek. Inform. dan Sist. Inf., vol. 2, no. 2, pp. 162-172, 2016.

[14] G. A. Romanta, "Simulasi Vehicular Ad Hoc Network (Vanet) Menggunakan Openstreetmap Dengan Simulation Of Urban Mobility (Sumo) Dan Omnet 
$++, " 2017$

[15] P. K. Singh, "Comparative Study of Radio Propagation and Mobility Models in Vehicular Adhoc Network," Int. J. Comput. Appl. (0975, vol. 16, no. 8, pp. 37-42, 2011.
[16] F. Mapa, S. Djanali, and A. M. S., "Optimasi OLSR Routing Protocol Pada Jaringan Wireless Mesh Dengan Adaptive Refreshing Time Interval Dan Enhance Multi Point Relay Selecting Algorithm," vol. 12, no. 1, pp. 44-49, 2014. 